\title{
Proposed Maintenance Policy And Economical Age Using Risk Based Maintenance Method And Remaining Life Assessment: A Case Study On Co Absorbent Pumps
}

\author{
Sophia Yasmine Agnaputri ${ }^{1}$, Judi Alhilman ${ }^{2}$, Fransiskus Tatas Dwi Atmaji ${ }^{3}$ \\ School of Industrial and System Engineering Telkom University, Bandung, 40257, Indonesia \\ sophiayasmineap@gmail.com¹, alhilman@telkomuniversity.ac.id², franstatas@telkomuniversity.ac.id ${ }^{3}$

\begin{abstract}
Manufacturing Company is a company that carries out the production process from raw materials into goods that have sale value, the use of machinery is very important for the production process. The use of machines is very important because when a machine fails then the production process must stop and the company suffers a loss due to the failure. This can occur due to excessive use of machinery, to reduce this it is necessary to take action or maintenance policies. The purpose of this research is to assess the risk of failure due to a decrease in engine performance, an assessment of the economic life of the engine, and maintenance policies whether to use an old machine or replace it with a new engine. The method used is Risk-Based Maintenance (RBM) which is used to calculate the value of failure risk due to engine failure and Remaining life assessment used to assess the economic life of the machine, the risk value, and the economic life of the machine are used to determine maintenance policies. Based on the calculation of risk-based maintenance, the failure risk value is Rp. Rp. 440,451,691 or in the form of a percent of $2 \%$. Based on the Remaining Life Assessment method by comparing the economic lives of two options (the use of an old machine and the use of a new machine), a policy should be made to replace the machine with a new one.
\end{abstract}

Keywords: Risk Based Maintenance, Remaining Life Assessment, Replacement Analysis, Risk Value, Economic Age of Machine

\section{Introduction}

The manufacturing industry sector is a sector that carries out the production process from raw materials into finished goods which has a selling value, in carrying out the process machinery is an important asset to support the production process. PT. $\mathrm{X}$ is a company that processes $\mathrm{CO}$ gas production, where the $\mathrm{CO}$ gas is purified and produces $\mathrm{CO}$ solutions that are sold to consumers. PT. This X uses a machine called CO absorbent pump to carry out the CO purification process. The pump is often damaged due to excessive use of critical components and the $\mathrm{CO}$ solution contains copper which can damage the pump wall and the pump can fail.

So, this research was conducted at PT. X which produces $\mathrm{CO}$ solutions with $\mathrm{CO}$ absorbent pumps, which often results in failure or damage to the pump due to excessive use of some components. So that the calculation of the risk value of failure using the RBM method, the value of the failure risk is used as one of the variables in the assessment of pump life based on the calculation of total risk. This calculation of total risk is assisted by the calculation of $\mathrm{UAC}$ to calculate the total risk in subsequent years and the selection of economic age based on the EUAC of minimum risk. The calculation of the total risk is carried out for both options, 
option 1 for the old pump and option 2 for the new pump. After calculating the total risk of each option, a comparison of the total risk and economic life of the two options is made to determine the maintenance policy (use of the old pump or replacement with a new pump).

\section{Literature Review}

Based on research conducted [1], the use of risk-based maintenance can be used to determine maintenance policies. The calculation of Risk-based maintenance or RBM according to [2], can be used to calculate the value of the risk of failure that occurs due to a decrease in pump performance, when the percentage of risk values exceeds the company's acceptance criteria, then the company suffers a loss. Conducted using risk-based maintenance (RBM) which is used for research related to inspection, repair, scheduled cleaning and machine replacement in manufacturing companies to ensure operational reliability and final product quality. In the study, the equipment or machinery used experienced aging and decreased productivity, the resulting product has a quality that decreases along with the state of the machine [3]. Risk-based maintenance is used to predict and analyze risk factors for pipe failures and suggest maintenance policies [4]. By using risk-based maintenance and inspection, an optimal life cycle risk analysis can be carried out [5].

On maintenance for wind turbines generally include corrective maintenance and proactive maintenance. This treatment is divided into two preventive maintenance (scheduled maintenance) and predictive maintenance, in the case in this study environmental conditions such as wind can cause the degradation pattern of the turbine [6]. Damage data can be used to assess the life of the machine by using the estimated engine characteristics (reliability, probability of failure and failure rate) [7]. The calculation of risk of failure using a risk-based maintenance method can help determine maintenance policies. The calculation of the risk of failure is calculated based on the probability of failure and the consequence of failure [8]. Research on making a prediction model for conducting inspection and planning maintenance. In this study the inspection plan was made based on the potential damage and focused on the condition of the structure, this inspection plan was carried out to increase efficiency.

This study presents a methodology for testing damage to structures in which the data taken is based on expert judgment. This methodology will be used to improve inspection and maintenance planning [9]. Maintenance carried out for offshore wind turbines is carried out with risk-based maintenance. By using Bayesian statistical calculations that are used to estimate and update the likelihood of risks, while cost models are made using a cost and degradation model. Costs for maintenance policies are taken from annual Operation and Maintenance costs. In this case, risk-based maintenance or RBM is used to make an inspection plan and determine an optimal repair policy for each inspection [10]. Risk of failure is one of the variables used to calculate remaining life assessments based on the calculation of total risk (replacement costs, repair costs, operating costs and risk of failure) to determine the economic age and maintenance policy is to compare the two options (old pump and new pump) [8]. According to [11], the calculation of economic age can be helped by the use of the calculation of equivalent uniform annual cost or EUAC, where the economic age is equal to the minimum EUAC. 


\section{Methods}

\subsection{Risk Based Maintenance}

RBM calculation is carried out to determine the value of risk caused by failure according to [12], there are three stages, namely the risk estimation stage, the risk evaluation stage and the maintenance planning stage. The risk estimation stage is the stage of compiling failure scenarios. The risk evaluation stage is the calculation of the probability of failure and the consequence of failure. The maintenance stage is the stage for carrying out the optimal maintenance strategy. The following is a calculation of the value of risk or risk of failure based on research conducted by [8]:

$\mathrm{R}_{\mathrm{f}}=\mathrm{P}_{\mathrm{f}} \times \mathrm{C}_{\mathrm{f}}$

\subsection{Probability of Failure}

Failure calculation is the chance of failure due to the unreliable $(\mathrm{Rm})$ of the critical component. The following is a calculation of the probability of failure based on [8]:

$P_{f}=1-R_{m}$

\subsection{Consequence of Failure}

The calculation of the consequences of failure is done by assessing system performance loss (SPL), Consequence assessment is a combination of four categories of consequences in the form of System Performance Loss, Financial Loss, Human Health Loss, and Environment and Ecological Loss. Where there are variables Mean downtime, loss of revenue, mean time to repair, engineering cost, component cost, the following is a calculation of the consequence of failure based on research [1]:

$\mathrm{SPL}=(M D T \times L O R)+(M T T R \times E C)+M C+\mathrm{CC}$

\subsection{Remaining Life Assessment}

Remaining life assessment is used to assess the life of critical components and pumps and to determine maintenance policies by comparing the total risk and economic life of two options, namely defender (option 1) and challenger (option 2), the following is a formula for calculating total risk [8]:

$\mathrm{RT}=\sum_{\mathrm{Nu}}($ Crep + Co.t + Crepair $)+\mathrm{Rf}-\sum_{\mathrm{Nu}} \mathrm{Rv}$

\subsection{Replacement Cost}

Replacement cost for option 1 is overhaul (current market value) because option 1 uses an old pump, the company overhauls to improve the pump's performance in carrying out its functions.

EUAC of Replacement Cost $=$ Replacement Cost $\times(\mathrm{A} / \mathrm{P}, \mathrm{i}, \mathrm{n})$ 


\subsection{Operation Cost}

Operating costs are costs used by the company during production activities or costs incurred due to operating pumps. Costs included in operating costs are employee salaries, electricity, water, and telephone and office administration costs.

EUAC of Operation Cost $=$ Operation Cost $+[$ Gradient Cost $\times(\mathrm{A} / \mathrm{G}, \mathrm{i}, \mathrm{n})]$

\subsection{Repair Cost}

Repair costs are costs used to perform maintenance and repairs on each critical component when there is a failure on each critical component, this cost data is obtained from the company. Repair costs are obtained from the average repair costs from the previous year and divided by maintenance intervals.

\subsection{Risk of Failure}

The cost of risk of failure is the cost caused by the risk of damage due to the failure of critical components at the pump. For risk of failure option 1 is obtained from the calculation of the risk value using the Risk-Based Maintenance or RBM method, while for option 2 it is assumed the parameter $\eta$ value is greater than option 1 where when $\eta$ is greater the risk value will be smaller because option 2 is a pump incipient risk value of option 2 is smaller than option 1 .

\section{Result and Discussion}

\subsection{Data Collection and Procecing}

Data collection was carried out in company $\mathrm{X}$ by recapitalizing historical data and conducting interviews with employees of the Maintenance and Reliability Planning (Renhar and Reliability) division of PT. XYZ to get information about the existing conditions of the CO absorbent pump (P-201) at the company PT. XYZ, the data is used for data processing in this study. The historical data are pump damage data from 2017-2019, machine life data, production data, machine price data, equipment costs, employee costs, machine maintenance costs and other data.

\subsection{Calculation of Risk Based Maintenance}

Before calculating the RBM, a critical component is determined using a risk matrix to determine three critical components, namely bearing ball, mech seal, and impeller. After that, determining the distribution to calculate the value of MTTR, MTTF, and MDT uses Minitab software (determination of distribution) and Avsim (determination of parameter values).

\subsection{Calculation of Probability Failure}

Probability of Failure is a calculation carried out to find out the probability of failure (Pf) that can occur in every critical component of the pump in one year, with pump operating times 
that have been reduced with a breakdown interval in 1 the year of 2036 hours.

Table 1. Probability of Failure

\begin{tabular}{cccc}
\hline $\begin{array}{c}\text { Critical } \\
\text { Component }\end{array}$ & Distribution & Rm & Pf \\
\hline Bearing Ball & Weibull & 0,286 & 0,714 \\
Mechseal & Weibull & 0,347 & 0,653 \\
Impeller & Weibull & 0,387 & 0,613 \\
\hline
\end{tabular}

$\mathrm{R}(\mathrm{T})$ is the reliability or strength of a component to work by its function in a period of 2284 hours, while Q (T) is a chance of failure that can occur due to damage to critical components during a period of 2036 hours.

\subsection{Calculation of The Consequences of Failure}

The calculation of the consequences of failure is done to calculate the value of the consequences caused by a decrease in system performance loss (SPL). The following is the SPL calculation:

Table 2. Consequence of Failure

\begin{tabular}{cccccccc}
\hline $\begin{array}{c}\text { Critical } \\
\text { Component }\end{array}$ & MDT & MTTR & $\begin{array}{c}\text { Loss of } \\
\text { Revenue }\end{array}$ & $\begin{array}{c}\text { Material } \\
\text { Cost }\end{array}$ & $\begin{array}{c}\text { Engineer } \\
\text { Cost }\end{array}$ & $\begin{array}{c}\text { Component } \\
\text { Prices }\end{array}$ & SPL \\
\hline $\begin{array}{c}\text { Bearing } \\
\text { ball }\end{array}$ & 4,278 & 3,324 & $\mathrm{Rp}$ & $\mathrm{Rp}$ & $\mathrm{Rp} 160.014$ & $\mathrm{Rp}$ & $\mathrm{Rp}$ \\
Mechseal & 5,211 & 3,809 & 41.318 .817 & 1.124 .472 & $\mathrm{Rp}$ & 10.762 .248 & 189.162 .706 \\
& & $\mathrm{Rp}$ & $\mathrm{Rp}$ & $\mathrm{Rp} 160.014$ & $\mathrm{Rp}$ & $\mathrm{Rp}$ \\
Impeller & 4,106 & \multirow{2}{*}{3,097} & 47.351 .935 & 1.124 .472 & & 24.480 .000 & 272.953 .468 \\
& & & $\mathrm{Rp}$ & $\mathrm{Rp}$ & $\mathrm{Rp} 160.014$ & $\mathrm{Rp}$ & $\mathrm{Rp}$ \\
& & & 38.503 .660 & 1.124 .472 & & 48.000 .000 & 207.730 .724 \\
\hline
\end{tabular}

System Performance Loss is the cost incurred due to a decrease in system performance caused by pump stops, pump repairs, and several variables that affect losses such as loss of revenue, material costs, engineer costs, and component prices.

\subsection{Calculation of The Risk of Failure}

Next is calculating the risk value or risk of failure due to failures that occur on the machine for each critical component, the following is a calculation of the risk value based on the probability of failure $\mathrm{Q}(\mathrm{T})$ or $\mathrm{P}(\mathrm{f})$ on each critical component:

Table 3. Risk of Failure

\begin{tabular}{ccc}
\hline Critical Component & $\mathbf{Q}(\mathbf{T})$ & Risk Value (Rp.) \\
\hline Bearingball & 0,71366632 & $\mathrm{Rp} \mathrm{134.999.052}$ \\
Mechseal & 0,652545819 & $\mathrm{Rp} \mathrm{178.114.644}$ \\
Impeller & 0,612995481 & $\mathrm{Rp} \mathrm{127.337.995}$ \\
TOTAL & & $\mathrm{Rp} \mathrm{440.451.691}$ \\
\hline
\end{tabular}

Table 4. Determination of Risk Acceptance Criteria

\begin{tabular}{cccccc}
\hline Period (Hour) & Hourly Rate & $\begin{array}{c}\text { Production } \\
\text { capacity in 1 year }\end{array}$ & Risk Value & \%Risk & Acceptance criteria \\
\hline $\mathbf{2 0 3 6}$ & $\mathrm{Rp} 12.432 .000$ & $\mathrm{Rp} 25.307 .809 .358$ & $\mathrm{Rp} 440.451 .691$ & $2 \%$ & $1 \%$ \\
\hline
\end{tabular}


Based on table 4, with a period of 2036 hours for one year and an hourly rate of Rp. $12,432,000$ so that the production capacity of 1 year $\mathrm{CO}$ absorbent pumps is $\mathrm{Rp}$. $25,307,809,358$. Therefore, by dividing the production capacity by the total risk, the risk acceptance criteria received by the company for one year are greater than the revenue criteria from the company, which is $2 \%$ for one year.

\subsection{Calculation of Remaining life assessment}

This calculation is carried out for maintenance strategies and to assess the remaining life or see the economic life for each critical component and also the economic life of the pump, this calculation can also be used to determine the pump change policy or keep the old pump by comparing the total risk between pumps defender (Option 1) and challenger pump (Option 2).

\subsection{Calculation of Economical Age for Critical Components (Option 1)}

Calculation of defender pump or old pump or option 1 overhaul to improve pump performance so that it functions according to the standard (replacement cost) so that the pump can be reused for the next 5 years, repair costs for the first and second year are the same because there is a period of useful life while the following year has a gradient increase for ball bearing components of Rp. 308,417, for a mech seal of Rp. 559,639, for the impeller Rp. 932,749 , and the defender pump has no residual value. The following is a calculation of the total risk for critical component option 1.

Table 5. The Total Risk of Bearing Ball for Option 1

\begin{tabular}{|c|c|c|c|c|c|c|}
\hline Year & Replacement Cost & Operation Cost & Repair Cost & Risk Of Failure & Total & Optimal Age \\
\hline 1 & Rp 14.031.961 & Rp 81.160.014 & Rp 6.168.340 & Rp 134.999.052 & Rp 236.359.367 & \multirow{5}{*}{2 Year } \\
\hline 2 & $\mathrm{Rp} 7.286 .226$ & Rp 83.111.913 & Rp 6.168 .340 & Rp 134.999.052 & Rp 231.565.530 & \\
\hline 3 & $\operatorname{Rp} 5.041 .112$ & Rp 84.978.593 & Rp 6.263 .332 & Rp 137.078.038 & Rp 233.361.075 & \\
\hline 4 & Rp 3.922 .453 & Rp 86.857.447 & Rp 6.379.127 & Rp 139.612.300 & Rp 236.771.327 & \\
\hline 5 & $\operatorname{Rp} 3.254 .635$ & Rp 88.651.084 & Rp 6.500 .971 & Rp 142.278 .953 & Rp 240.685 .643 & \\
\hline
\end{tabular}

Table 6. The Total Risk of Mechseal for Option 1

\begin{tabular}{|c|c|c|c|c|c|c|}
\hline Year & Replacement Cost & Operation Cost & Repair Cost & Risk Of Failure & Total & Optimal Age \\
\hline 1 & Rp 21.047.941 & $\operatorname{Rp} 81.160 .014$ & Rp 11.192.788 & Rp 178.114.644 & Rp 291.515.388 & \\
\hline 2 & Rp 10.929.338 & Rp 83.111.913 & Rp 11.192.788 & Rp 178.114.644 & Rp 283.348.684 & \\
\hline 3 & Rp 7.561.668 & Rp 84.978.593 & Rp 11.365.157 & Rp 180.857.610 & Rp 284.763.028 & 2 Year \\
\hline 4 & Rp 5.883.679 & Rp 86.857.447 & Rp 11.575.273 & Rp 184.201.257 & $\mathrm{Rp} 288.517 .657$ & \\
\hline 5 & Rp 4.881 .953 & $\operatorname{Rp} 88.651 .084$ & Rp 11.796.366 & Rp 187.719.579 & Rp 293.048.981 & \\
\hline
\end{tabular}

Table 7. The Total Risk of Impeller for Option 1

\begin{tabular}{|c|c|c|c|c|c|c|}
\hline Year & Replacement Cost & Operation Cost & Repair Cost & Risk Of Failure & Total & Optimal Age \\
\hline 1 & Rp 35.641.602 & $\operatorname{Rp} 81.160 .014$ & Rp 18.654.986 & Rp 127.337.995 & Rp 262.794.597 & \\
\hline 2 & Rp 18.507.232 & Rp 83.111.913 & Rp 18.654.986 & Rp 127.337 .995 & $\operatorname{Rp} 247.612 .125$ & \\
\hline 3 & Rp 12.804.575 & Rp 84.978.593 & Rp 18.942.273 & Rp 129.299 .000 & Rp 246.024.441 & 3 Year \\
\hline 4 & Rp 9.963.148 & Rp 86.857.447 & Rp 19.292.472 & Rp 131.689.446 & Rp 247.802.513 & \\
\hline 5 & Rp 8.266.872 & Rp 88.651.084 & Rp 19.660.967 & Rp 134.204 .769 & $\operatorname{Rp} 250.783 .691$ & \\
\hline
\end{tabular}

Based on the three tables above, the four costs are calculated in advance of the EUAC to 
determine the annual costs to be paid, after which the total risk is calculated where the EUAC of replacement costs, EUAC of repair costs, EUAC of operation costs and EUAC of risk failure are added together. After calculating each cost paid annually (EUAC), the next step is to calculate the total risk of each component by adding up the costs. To obtain the economic age of each component following the minimum total risk (in the optimal age column).

\subsection{Calculation of Economical Age for Critical Components (Option 2)}

The economic life calculation for critical components for option 2 is calculated by EUAC before calculating the total risk where there is a provision in option 2, namely, option 2 uses a new component so that the pump life is 6 years, operating costs in option 2 are the same as in option 1, Repair costs for the first year are guaranteed so in the first year the repair costs are Rp. 0, while the following year the gradient cost increase for ball bearing components was Rp. 154,208 , for mech seal Rp. 279,820, for the impeller Rp. 466,375. To obtain the cost of risk of failure, the parameter $\eta$ from time to failure is assumed to be greater than option 1, which is for ball bearings $\eta=4851.33$, for mech seal $\eta=7611.56$, for impeller $\eta=11047.7$ so that the risk value for each critical component is obtained. It has no residual value. The following are the results of the total risk and economic life of the three critical components:

Table 8. The Total Risk of Bearing ball for Option 2

\begin{tabular}{|c|c|c|c|c|c|}
\hline \multicolumn{2}{|c|}{ Year Replacement Cost } & \multirow{2}{*}{$\begin{array}{r}\text { Operation Cost } \\
\text { Rp } 81.160 .014\end{array}$} & \multirow{2}{*}{$\frac{\text { Repair Cost }}{\mathrm{Rp}-}$} & \multirow{2}{*}{$\begin{array}{c}\text { Risk Of Failure } \\
\text { Rp } 36.887 .462\end{array}$} & \multirow{2}{*}{$\begin{array}{l}\text { Total } \\
\text { Rp 148.115.963 }\end{array}$} \\
\hline 1 & Rp 30.068 .487 & & & & \\
\hline 2 & Rp 15.613 .340 & Rp 83.111.913 & Rp 5.730.987 & Rp 36.887 .462 & Rp 141.343.702 \\
\hline 3 & Rp 10.802 .383 & Rp 84.978.593 & Rp 5.859.705 & Rp 37.455 .528 & Rp 139.096.208 3 Year \\
\hline 4 & Rp 8.405.256 & Rp 86.857.447 & Rp 5.989.261 & Rp 38.147.996 & Rp 139.399.961 \\
\hline 5 & Rp 6.974.219 & Rp 88.651.084 & Rp 6.112 .941 & Rp 38.876.639 & Rp 140.614.883 \\
\hline 6 & Rp 6.022 .050 & Rp 90.396 .024 & $\operatorname{Rp} 6.233 .264$ & Rp 39.610 .506 & Rp 142.261 .843 \\
\hline
\end{tabular}

Table 9. The Total Risk of Mechseal for Option 2

\begin{tabular}{|c|c|c|c|c|c|c|}
\hline Year & Replacement Cost & Operation Cost & Repair Cost & Risk Of Failure & Total & Optimal Age \\
\hline 1 & Rp 41.570 .843 & Rp 81.160.014 & $\mathrm{Rp}-$ & Rp 31.218.020 & Rp 153.948.878 & \\
\hline 2 & Rp 21.586.045 & Rp 83.111.913 & $\operatorname{Rp} 9.551$. & Rp 31.218.020 & Rp 145.467.797 & \\
\hline 3 & Rp 14.934.710 & $\operatorname{Rp} 84.978 .593$ & Rp 9.766.352 & Rp 31.698 .778 & Rp 141.378.433 & ears \\
\hline 4 & Rp 11.620.590 & Rp 86.857.447 & Rp 9.982.283 & Rp 32.284.816 & Rp 140.745.137 & \\
\hline 5 & Rp 9.642.126 & Rp 88.651.084 & Rp 10.188.421 & Rp 32.901 .470 & Rp 141.383.100 & \\
\hline 6 & Rp 8.325.716 & Rp 90.396.024 & Rp 10.388.962 & Rp 33.522 .545 & Rp 142.633.246 & \\
\hline
\end{tabular}

Table 10. The Total Risk of Impeller for Option 2

\begin{tabular}{|c|c|c|c|c|c|c|}
\hline Year & Replacement Cost & Operation Cost & Repair Cost & Risk Of Failure & Total & Optimal Age \\
\hline 1 & Rp 91.684.989 & $\mathrm{Rp} 243.480 .043$ & $\mathrm{Rp}-$ & Rp 98.753.951 & Rp 433.918.983 & \\
\hline 2 & Rp 47.608.279 & Rp 249.335 .738 & Rp 18.441.151 & Rp 98.753.951 & Rp 414.139.119 & \\
\hline 3 & Rp 32.938.681 & Rp 254.935.779 & Rp 18.855 .336 & Rp 100.274 .762 & Rp 407.004.558 & 3 years \\
\hline 4 & $\operatorname{Rp} 25.629 .350$ & Rp 260.572.342 & Rp 19.272.223 & Rp 102.128.615 & $\operatorname{Rp} 407.602 .530$ & \\
\hline 5 & $\mathrm{Rp} 21.265 .824$ & Rp 265.953 .251 & Rp 19.670.201 & Rp 104.079.314 & Rp 410.968.590 & \\
\hline 6 & Rp 18.362.466 & Rp 271.188.072 & Rp 20.057.374 & Rp 106.043 .999 & Rp 415.651.911 & \\
\hline
\end{tabular}

The calculation of the four costs in tables 8 to 10 uses the calculation of EUAC, EUAC of replacement cost, namely the purchase value of new components that must be paid annually, EUAC of operation cost, which is the operating costs to be paid annually, EUAC of repair costs, namely maintenance costs from preventive maintenance must be paid annually where in 
the first year of option 2 there is a warranty so that repair costs are not paid, EUAC of risk failure is the cost paid or incurred due to a failure of critical components.

After calculating each cost paid annually (EUAC), the next step is to calculate the total risk of each component by adding up the costs. To obtain the economic age of each component following the minimum total risk (in the optimal age column).

\subsection{Maintenance Policy Analysis}

After calculating the total risk using EUAC on the three critical components, the next step is to determine the economic life for the pump. Based on research in the reference journal and according to the maintenance department at PT. XYZ that the economic life of the pump can be determined from the sum of the total EUAC risks of the three components. The following are the total risks and economic lives of option 1 and option 2.

\subsection{Calculation of Total Pump Risk Option 1 and Option 2}

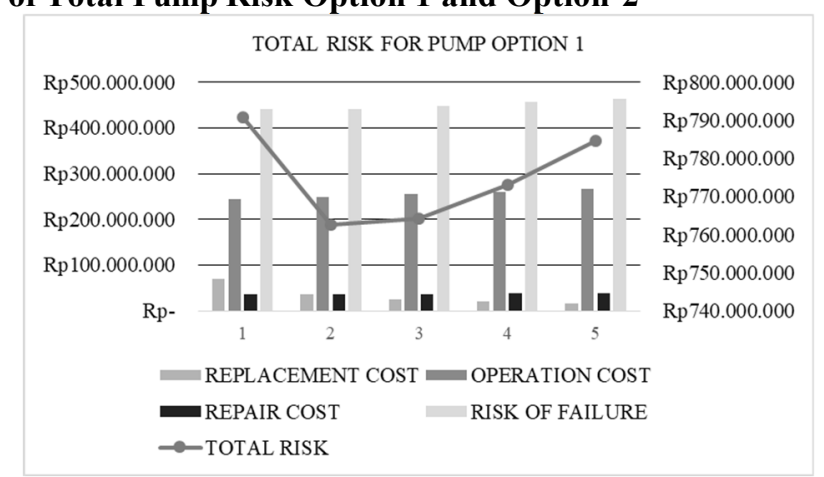

Fig. 1. The Total Risk For Pump Option 1

Based on the graph data in Figure 4, the lowest total EUAC is in the second year. The total risk in the figure is obtained from the sum of the total risks from the three critical components, after the total risk is added up the total risk for the option 1 pump has the lowest cost in the second year. Then based on the EUAC calculation of total risk, option pump 1 has an economic life of two years after overhaul, with the total cost of risk to be paid annually for 2 years of Rp. 762,526,339.

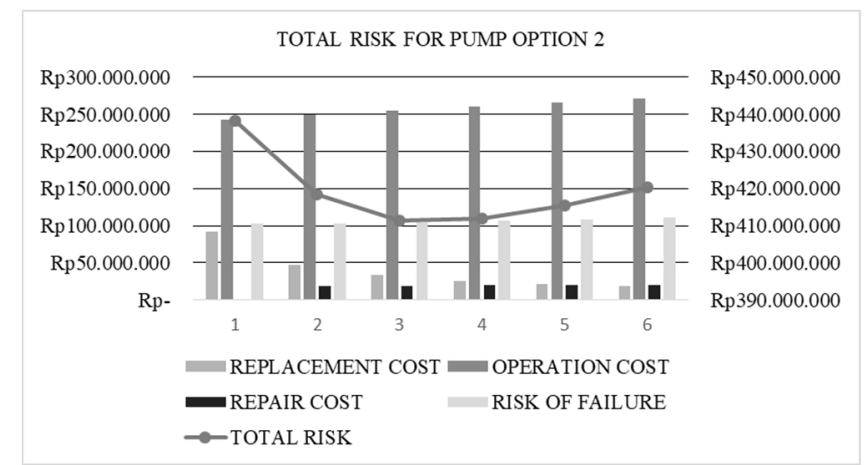

Fig.2. The Total Risk For Pump Option 2 
Based on the graph data in Figure 5, the lowest total EUAC is in the fourth year. The total risk in the figure is obtained from the sum of the total risks from the three critical components, after the total risk is added up the total risk for option pump 2 has the lowest cost in the third year. Then based on the calculation of EUAC total risk, option pump 2 has an economic life for three years after the purchase of a new pump in year 0 , with a total risk cost that must be paid for four years at Rp. 407,004,558.

\section{Conclusion}

Based on research that has been done on $\mathrm{CO}$ absorbent pumps, the following conclusions can be drawn:

a) Based on the calculation of the value of the risk of failure or risk of failure due to unreliable in $\mathrm{CO}$ absorbing pumps caused by a failure of the three critical components, in a period of one year or 2036 hours using the risk-based maintenance method, the risk that must be borne by the company is equal to Rp. 440,451,691 or in the form of a percent of $2 \%$. The value of failure risk exceeds the risk of acceptance criteria that is equal to $1 \%$ of the production capacity for one year, so the maintenance policy is needed to reduce the risk that must be borne by the company.

b) Based on the calculation of EUAC the total risk to determine the economic life of the three critical components in both options (defender and challenger) is determined by looking at the minimum EUAC, so that option 1 or defender for critical components of ball and mech seal bearings has an economic life of two years and for impeller have an economic age of 3 years. For the three critical components in option 2 or challenger namely ball bearings, mech seal, and impeller have an economic life of three years, three years, and four years, respectively.

c) To reduce the risk that must be borne by the company one of them by determining the maintenance policy that is to keep using the old pump or replace it with a new one. Based on the calculation of EUAC, the total risk of the three critical components for option pump 1 is that the defender has an economic life of two years with a total risk caused by the failure of the three critical components of Rp. 762,526,339, while pump option 2, challenger, has an economic life of three years with a total risk caused by a failure of three critical components of Rp. 407,004,558. So after comparing the two options the best results are obtained by replacing the defender pump with a challenger pump.

\section{Acknowledgement}

The authors express grateful acknowledgment to the company $\mathrm{X}$ has helped the authors. Thank you to Telkom University for supporting this research especially to the faculty of industrial engineering. Authors would like to thank Pelita Bangsa University for organizing a Internasional Conference on Economic Engineering and Social Science. 


\section{References}

[1] F. I. Khan, R. Sadiq, and M. M. Haddara, "Risk-based inspection and maintenance (RBIM) multiattribute decision-making with aggregative risk analysis," Process Saf. Environ. Prot., 2004.

[2] D. S. Dhamayanti, J. Alhilman, and N. Athari, "Usulan Preventive Maintenance Pada Mesin Komori Ls440 Dengan Menggunakan Metode Reliability Centered Maintenance (Rcm Ii) Dan Risk Based Maintenance (Rbm) Di Pt Abc,”J. Rekayasa Sist. Ind., vol. 3, no. 02, p. 31, 2016.

[3] R. M. C. Ratnayake and K. Antosz, "Development of a Risk Matrix and Extending the Riskbased Maintenance Analysis with Fuzzy Logic,” Procedia Eng., vol. 182, no. 1877, pp. 602-610, 2017.

[4] P. K. Dey, "A risk-based model for inspection and maintenance of cross-country petroleum pipeline," J. Qual. Maint. Eng., vol. 7, no. 1, pp. 25-41, 2001.

[5] Y. Dong and D. M. Frangopol, "Risk-informed life-cycle optimum inspection and maintenance of ship structures considering corrosion and fatigue," Ocean Eng., vol. 101, pp. 161-171, 2015.

[6] X. Lei and P. A. Sandborn, "Maintenance scheduling based on remaining useful life predictions for wind farms managed using power purchase agreements," Renew. Energy, vol. 116, pp. 188$198,2018$.

[7] J. Alhilman, "RELIABILITY BASED PERFORMANCE ANALYSIS OF BASE TRANSCEIVER STATION ( BTS ) USING RELIABILITY, AVAILABILITY , AND MAINTAINABILITY ( RAM ) A ( t ) Jan MarMei Juli SepNov month,” Int. Semin. Ind. Eng. Manag., pp. 1-6, 2016.

[8] M. Khalifa, F. Khan, and J. Thorp, "Risk-based maintenance and remaining life assessment for gas turbines," J. Qual. Maint. Eng., vol. 21, no. 1, pp. 100-111, 2015.

[9] N. Hifi and N. Barltrop, "Correction of prediction model output for structural design and riskbased inspection and maintenance planning," Ocean Eng., vol. 97, pp. 114- 125, 2015.

[10] M. Florian and J. D. Sørensen, "Risk-based planning of operation and maintenance for offshore wind farms," Energy Procedia, vol. 137, pp. 261-272, 2017.

[11] M. Giatman, Ekonomi Teknik. 2005.

[12] N. S. Arunraj and J. Maiti, "Risk-based maintenance-Techniques and applications," J. Hazard. Mater., 2007. 